Original article

\title{
Features of cytokine and adipokine regulation in asthma associated with obesity
}

\author{
Alla V. Yurenko, Marina V. Antonyuk, Elena E. Mineeva, Tatyana P. Novgorodtseva, Kira K. Khodosova
}

Research Institute of Medical Climatology and Rehabilitative Treatment, Vladivostok, Russia

Received 24 June 2018, Revised 25 December 2018, Accepted 13 May 2019

(C) 2018, Yurenko A.V., Antonyuk M.V., Mineeva E.E., Novgorodtseva T.P., Khodosova K.K.

(C) 2018, Russian Open Medical Journal

Abstract: The aim is to establish interrelations between levels of cytokines and adipokines in blood serum of patients with asthma; to reveal the features of cytokine and adipokine regulation in asthma associated with obesity.

Material and Methods - We examined 71 patients with partially controlled mild asthma: 24 normal-weight patients (group 1), 24 overweight patients (group 2), 23 patients with grade I and II obesity (group 3). The control group consisted of 25 healthy volunteers. Blood serum levels of Tumour necrosis factor alpha (TNF- $\alpha$ ), interferon gamma (IFN- $\gamma$ ), interleukin-2 (IL-2), IL-4, IL-6, IL-10, and IL-17A were studied by flow cytometry. The concentrations of leptin and adiponectin were measured by an enzyme immunoassay.

Results - Increase levels of TNF- $\alpha$, IL-6, IL-17A and IL- 4 have been found in asthma patients regardless of body weight. At the same time, IL- 6 level in the groups 2 and 3 was 1.4 times higher than in group 1. IL-17A level in patients with asthma and obesity was 1.2 times higher than in the groups 1 and 2. The elevation of IL-10 level in 1.8 and 2.3 times in patients of groups 2 and 3 in comparison with the group 1 , respectively, has been determined. Hyperleptinemia was detected in the groups 2 and 3 . A positive correlation between the body mass index and the levels of leptin, IL-4, IL-6, IL-10, IFN- $\gamma$ and an invert correlation between this index and adiponectin concentration has been established. The interrelations between the levels of leptin, pro- and anti-inflammatory cytokines, depending on the body weight, have been revealed.

Conclusion - The production of pro-inflammatory cytokines IL-6 and IL-17A, as well as anti-inflammatory cytokine IL-10 enhances in asthma patients as the body weight increases and the obesity develops. The features of cytokine and adipokine imbalance indicate the prevalence of neutrophilic inflammation in asthma with obesity and demonstrates pathogenetic link between obesity and asthma.

Keywords: asthma, overweight, obesity, cytokines, adipokines.

Cite as Yurenko AV, Antonyuk MV, Mineeva EE, Novgorodtseva TP, Khodosova KK. Features of cytokine and adipokine regulation in asthma associated with obesity. Russian Open Medical Journal 2019; 8: e0203.

Correspondence to Alla V. Yurenko. Address: Russkaya str. 73g, Vladivostok, 690105, Russia. E-mail: yurenko_alla@mail.ru. Phone: +7(924)240-68-09.

\section{Introduction}

Currently, asthma remains one of the global public health problems. Epidemiological studies have shown an increase in the number of patients with asthma and obesity. It is believed that obesity may be a risk factor for asthma development. According to studies, the risk for the development of the disease in the background of overweight is $28 \%$ [1-2].

Chronic persistent inflammation as a reaction to various allergens and nonspecific stimuli underlies asthma pathogenesis regardless of disease severity [3]. Cytokines, which are the most intensively produced by T-helper (Th) cells and macrophages, play an important role in the regulation of immune response. The multifunctionality of their action due to the localization of receptors on different cell subpopulations and the presence of several types of receptors for one cytokine is known [4]. When analyzing the role of cytokines in a systemic inflammatory response, it is important to consider the effect of various mediators, including hormonal ones, on immunity [5].
Various mechanisms of the pathogenetic impact of obesity on asthma course are discussed in the literature. At the present time, an increased risk for asthma in overweight people is associated with the biological activity of adipose tissue. Understanding the role of metabolic and biological effects of adipokines allows us to consider their activity in the context of the main components of the pathogenesis of asthma with obesity [6-7].

Adipocytes and macrophages of adipose tissue are known to produce leptin, pro-inflammatory cytokines and other acute-phase proteins that lead to low intensive systemic chronic inflammation. The importance of leptin in innate and adaptive immunity has become known in recent years. It affects inflammation by enhancing the synthesis and release of leukotrienes by alveolar macrophages and lymphocytes. Despite numerous studies, the specific role of leptin in asthma is not fully defined [8-9].

Adiponectin is a key autocrine regulator of adipocyte secretion. Their main role is to reduce the release of interleukin-6 (IL-6), IL-8, growth regulators, monocyte chemoattractant protein1 , inflammatory proteins (MIP- $1 \alpha$, MIP- $1 \beta$ ). It is believed that the balance between anti-inflammatory (adiponectin) and pro- 
inflammatory (leptin, resistin) adipokines plays an important role in the association of obesity and asthma [10].

Nowadays, studies of the immune-metabolic features of asthma in overweight people are being conducted. Obtained results are often contradictory due to the heterogeneity of clinical manifestations of the disease [11-12]. The mechanisms and correlation links of cytokine and adipokine regulation in this pathology have not been sufficiently studied. The study of the interrelations between the levels of adipokines and cytokines and their interaction in asthma in people with different body weight helps to clarify the main pathogenetic mechanisms of this pathology.

The aim is to establish interrelations between levels of cytokines and adipokines in blood serum of patients with asthma; to reveal the features of cytokine and adipokine regulation in asthma associated with obesity.

\section{Material and Methods}

The study included 96 people: 71 patients with partially controlled mild asthma with different body weight and 25 healthy volunteers matched by sex and age with the patients (control group). Among the examined subjects were 39 men and 57 women aged $20-65$ years $(48.7 \pm 21.3$ years; data presented as mean with standard deviation). All test subjects gave an informed consent for inclusion prior to their participation in the study.

Inclusion criteria are partially controlled mild asthma, normal body weight, body overweight or alimentary constitutional obesity of I-II grades, 18-65 years of age.

Exclusion criteria are uncontrolled moderate and severe asthma, chronic obstructive pulmonary disease, occupational diseases of the bronchopulmonary system, endocrine diseases, alimentaryconstitutional obesity of III-IV grades, decompensated diseases of internal organs.

All patients underwent standard clinical, laboratory and functional examination in accordance with the standard of examination for asthma and alimentary-constitutional obesity. Asthma is diagnosed in accordance with the recommendations of Global Initiative for Asthma (GINA), 2017 [13]. The level of asthma control reflects the intensity of asthma symptoms or how decreased their severity under basic therapy. The criteria for a partially controlled asthma were the presence of 1 or 2 following symptoms in a patient over the past four weeks: daily symptoms were more often than twice a week; any night awakening caused by asthma; the need for short-acting $\beta_{2}$-agonists was more than twice a week; any activity restriction due to asthma [13]. ACQ-5 (Asthma Control Questionnaire) test score from 0.75 to 1.5 confirmed partial control of the disease [14]. The study of pulmonary function (PF) was performed using the apparatus "Master Screen Body" ("Care Fusion", Germany). Vital capacity (VC), forced vital capacity (FVC), forced expiratory volume in $1 \mathrm{sec}$ (FEV1) and FEV1/FVC were estimated. Salbutamol $(400 \mu \mathrm{g})$ was used to study airway obstruction reversibility. According to the latest recommendations of the European Respiratory Society (ERS) and the American Thoracic Society (ATS), the absolute and relative changes (bronchodilator coefficient) of FEV1 make it possible to accurately determine airway obstruction reversibility. If after inhalation of a short-acting bronchodilator the bronchodilator ratio is more than $12 \%$ and an absolute increase is more than $200 \mathrm{ml}$, a bronchodilator test is positive $[13,15]$.
To diagnose alimentary-constitutional obesity and determine its grade we calculated Quetelet's index (QI) using the formula: weight, $\mathrm{kg} /$ height, $\mathrm{m}^{2}$. According to the World Health Organization (WHO) recommendations, $\mathrm{Ql}=18.9-24.9 \mathrm{~kg} / \mathrm{m}^{2}$ is corresponded to normal body weight (NBW), $\mathrm{Ql}=25-29.9 \mathrm{~kg} / \mathrm{m}^{2}$ - body overweight (BOW), $\mathrm{Ql}=30-34.9 \mathrm{~kg} / \mathrm{m}^{2}$ - I grade obesity, IQ=35-39.9 kg/m² - II grade obesity and $\mathrm{QI}=40$ or more $\mathrm{kg} / \mathrm{m}^{2}-\mathrm{III}$ grade obesity [16]

After the examination, all patients with partially controlled mild asthma were divided into 3 groups depending on body weight. The Group 1 included 24 asthma patients with NBW (QI=22.39 \pm 2.32 $\left.\mathrm{kg} / \mathrm{m}^{2}\right)$, the Group 2 included 24 asthma patients with BOW ( $\mathrm{Ql}=27.95 \pm 1.45 \mathrm{~kg} / \mathrm{m}^{2}$ ), the Group 3 included 23 asthma patients with nutritional-constitutional obesity ( $\left.\mathrm{Ql}=32.8 \pm 3.29 \mathrm{~kg} / \mathrm{m}^{2}\right)$.

Serum concentrations of tumor necrosis factor- $\alpha$ (TNF- $\alpha$ ), interferon- $\gamma$ (IFN- $\gamma$ ), interleukins (IL) 2, 4, 6, 10, and 17A was determined by flow cytometry (test systems "Cytometric Bead Array", "BD", USA; cytometer "BD FACS Canto II", USA). "FCAP 3.0" software ("BD", USA) was used for data processing. Blood level of leptin and adiponectin was assessed by ELISA method using an enzyme immunoassay analyzer "STAT FAX 3200" (USA).

Statistical data processing was performed using the standard statistical software "Statistica 6.1" (StatSoft, USA). The hypothesis of normal distribution of quantitative traits in groups was tested using Kolmogorov-Smirnov, Shapiro-Wilk and Pearson $\chi^{2}$ criteria. The descriptive statistical data are expressed as $M \pm S D$ (for normal distribution; M, mean; SD, standard deviation) and Me (LQ, UQ) (for non-normal distribution; Me, median; LQ, lower quartile; UQ, upper quartile). The statistical significance of differences between alternative quantitative parameters was assessed using Student's ttest (for normal distribution) or Mann-Whitney and KolmogorovSmirnov tests (for non-normal distribution). The analysis of interrelations between pairs of parameters was carried out using the Spearman's correlation coefficient $(r) . \quad P<0.05$ being considered as significant.

\section{Results}

The analysis cytokine profile has revealed a statistically significant increase in levels of pro-inflammatory cytokines TNF- $\alpha$ IL6, IL-17A and anti-inflammatory cytokine IL-4 in asthma patients regardless of body weight (Table 1). At the same time, asthma patients exhibited a more significant elevation in the concentration of IL- 6 and IL-17A as their body weight increased. Thus, IL-6 level was 1.4 times higher in patients with BOW (Group 2) and obesity (Group 3) than in subjects of Group 1. The level of IL-17A was 1.2 times higher in patients with asthma associated with obesity compared to patients of Groups 1 and 2.

An increase in the level of anti-inflammatory cytokine IL-10 was characteristic for asthma patients with BOW and obesity. The concentration of this cytokine were increased by 1.5 and 2.9 times in patients of Groups 2 and 3 compared to patients of Group 1, respectively. It is important to note, that median values of IL-10 level was almost 2 times higher in obesity patients (Group 3 ) than in BOW patients (Group 2).

The study of adipose tissue activity has shown a statistically significant increase in serum leptin level in asthma patients compared to the control group regardless of Ql. The interquartile range of leptin level was increased by almost 3 times and 9 times in asthma patients with BOW and obesity compared to Group 1 and the control group, respectively. 
Table 1. Cytokine and adipokine profile in patients with asthma

\begin{tabular}{|c|c|c|c|c|}
\hline Parameters & Control group $(n=25)$ & $\begin{array}{l}\text { Group 1: normal-weight } \\
\text { asthma patients }(n=24)\end{array}$ & $\begin{array}{c}\text { Group 2: overweight asthma } \\
\text { patients }(n=24)\end{array}$ & $\begin{array}{c}\text { Group 3: patients with asthma } \\
\text { and obesity }(n=23)\end{array}$ \\
\hline Quetelet's index, $\mathrm{kg} / \mathrm{m}^{2}$ & $22.33 \pm 2.55$ & $22.39 \pm 2.32$ & $27.95 \pm 1.45$ & $32.80 \pm 3.36$ \\
\hline $\mathrm{IL}-2, \mathrm{pg} / \mathrm{ml}$ & $28.65(27.70,29.21)$ & $27.48(22.46,35.59)$ & $26.66(22.82,29.94)$ & $29.9(22.71,40.84)$ \\
\hline $\mathrm{IL}-4, \mathrm{pg} / \mathrm{ml}$ & $75.49 \pm 13.56$ & $169.26 \pm 44.34, \mathrm{p}_{1}<0.001$ & $167.96 \pm 45.44, \mathrm{p}_{1}<0.001$ & $176.07 \pm 61.72, p_{1}<0.001$ \\
\hline $\mathrm{IL}-6, \mathrm{pg} / \mathrm{ml}$ & $37.78 \pm 3.88$ & $56.46 \pm 21.41, \mathrm{p}_{1}=0.001$ & $80.66 \pm 32.92, p_{1}<0.001, p_{2}=0.014$ & $83.26 \pm 34.58, p_{1}<0.001, p_{2}=0.037$ \\
\hline $\mathrm{IL}-10, \mathrm{pg} / \mathrm{ml}$ & $33.10(30.98,35.23)$ & $28.90(22.24,38.81)$ & $\begin{array}{c}44.36(27.62,77.69), p_{1}=0.002 \\
p_{2}<0.001\end{array}$ & $\begin{array}{c}84.74(40.02,104.35) \\
p_{1}<0.001, p_{2}<0.001, p_{3}<0.001\end{array}$ \\
\hline $\mathrm{TNF}-\alpha, \mathrm{pg} / \mathrm{ml}$ & $38.93 \pm 8.43$ & $105.19 \pm 23.07, \mathrm{p}_{1}<0.001$ & $98.24 \pm 42.23, \mathrm{p}_{1}<0.001$ & $103.31 \pm 49.76, \mathrm{p}_{1}<0.001$ \\
\hline IFN- $\gamma, \mathrm{pg} / \mathrm{ml}$ & $107.77 \pm 10.98$ & $91.88 \pm 21.54$ & $87.78 \pm 33.21$ & $103.31 \pm 45.37$ \\
\hline $\mathrm{IL}-17 \mathrm{~A}, \mathrm{pg} / \mathrm{ml}$ & $352.16 \pm 69.95$ & $57.08 \pm 233.04, p_{1}<0.001$ & $582.20 \pm 196.06, \mathrm{p}_{1}<0.001$ & $\begin{array}{r}707.84 \pm 199.31, \\
p_{1}<0.001, p_{2}=0.029, p_{3}=0.038\end{array}$ \\
\hline Adiponectin, $\mu \mathrm{g} / \mathrm{ml}$ & $10.15(7.78,15.2)$ & $10.61(9.63,16.28)$ & $12.94(6.85,14.25)$ & $13.47(9.65,16.23)$ \\
\hline Leptin, $\mathrm{ng} / \mathrm{ml}$ & $8.9(5.48,12.43)$ & $14.74(6.25,27.55), \mathrm{p}_{1}=0.011$ & $\begin{array}{c}18.25(11.05,32.04) \\
p_{1}=0.007, p_{2}=0.024\end{array}$ & $\begin{array}{l}18.85(8.28,67.85) \\
p_{1}=0.004, p_{2}=0.018\end{array}$ \\
\hline
\end{tabular}

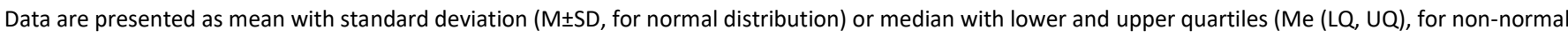
distribution).

$p_{1}$ - significance of differences compared to the control group; $p_{2}-$ significance of differences compared to the Group $1 ; p_{3}-$ significance of differences compared to the Group 2. Only values with $\mathrm{p}<0.05$ are given in the table.

The results of the analysis of interrelations between $\mathrm{QI}$ and levels of pro-, anti-inflammatory cytokines, adipokines are presented in Table 2. A positive correlation between $\mathrm{QI}$ and levels leptin, IL-4, IL-6, IL-10, IFN- - , and an invert correlation between $\mathrm{QI}$ and adiponectin have been found. The type and number of interrelations differed in groups of patients depending on body weight.

The largest number of statistically significant interrelations has been detected for IL-2 (with leptin, IFN- $\gamma$, IL-10) and IL-17A (with IL-6, TNF- $\alpha$, leptin) in asthma patients with NBW (Group 1). The highest number of interrelations between levels of leptin and cytokines (IL-2, IFN- $\gamma$, IL-17A, TNF- $\alpha$ ) as well as between leptin level and QI has been established in this group. An inverse interrelation between adiponectin level and QI has been identified.

The leading parameters in terms of the number of statistically significant correlations in asthma patients with BOW (Group 2) were IL-10 (with QI, IL-6, TNF- $\alpha$ ) and TNF- $\alpha$ (with leptin, IL-10, IL-17A). In contrast to Group 1, correlation links between QI and levels of cytokines such as IL-6, IL-10, IFN- $\gamma$ have been detected.

A significant increase in the secretion of IL-10 and IL-17A observed in patients with asthma associated with obesity (Group 3) affected the number of correlation links between these parameters and other studied ones in the group of patients. IL-10 level positively correlated with the concentrations of IL-4, IL-6, TNF- $\alpha$ and inversely did with IL-2 level. A positive correlation IL-17A with leptin, IL-4, IL-6, IL-10 and a negative correlation between IL-17A and IL-2 have been found.

\section{Discussion}

The obtained results indicate features of cytokine and adipokine status in asthma patients with different body weight.

The increase in the levels of TNF- $\alpha$, IL- 6, IL-17A and IL- 4 in all groups of patients suggests that they are inflammatory inductors in asthma, provide differentiation and maintain a balance between Thelper 1, 2 and 17 cells (Th1, Th2, Th17). It is consistent with the evidence that asthma is independently of the disease phenotype characterized by cytokine hyperproduction, which impact on the intensity of pro- and anti-inflammatory response $[17,18]$.
According to the literature, TNF- $\alpha$ determines the severity of bronchial hyperresponsiveness and is able to induce the synthesis of IL-6, IL-10, IL-17A [8]. The identified correlation links in groups of patients convincingly confirm this fact (Table 2).

The excess of IL- 6 level in Groups 2 and 3 as well as the identified correlation links allow us to consider this cytokine as a marker of an unfavorable course of the disease in patients with increased body weight. It is well known, that IL-6 contributes to the de-differentiation of T-regulatory cells (Treg) into Th17 cells and thereby leads to a decrease in the number of Tregs and the activation of autoimmune process $[18,19]$.

A statistically significant increase in IL-17A level in patients of Group 3 compared to Groups 1 and 2, established strong correlation connections with the main pro-inflammatory cytokines indicate the involvement of Th17-mediated immune mechanisms in the development and progression of the disease. It indicates the prevalence of neutrophilic inflammation in patients with asthma associated with obesity. According to the literature, Th17-lymphocytes and IL-17, IL-8, IL-32 play the main role in the formation of this type of inflammation. The production of IL-17A results in the activation of neutrophils and antimicrobial factors and the formation of an autoimmune inflammation [20].

An elevated level of anti-inflammatory cytokine IL-10 and the highest number of correlation links for it have been defined in asthma patients with obesity. IL-10 serves as a synergist for IL-4 as evidenced by an established direct correlation between these parameters. A negative association between IL-10 and IL-2 and its direct correlation with IL-17A indicate ambiguous role of this cytokine in inflammation. On the one hand, IL-10 suppresses the production of IL- 2 and IFN- $\gamma$ by T-lymphocytes and contributes to the activation of Th2 immune response. On the other hand, this mediator has immunosuppressive properties that are manifested through the induction of Treg cells into Th17 cells. In cases of an intensive inflammatory reaction, IL-10 can be secreted not only by macrophages, but also by antigen-non-specific $\mathrm{CD}^{+}$cells, that does not always indicate a prognostically favorable variant of the disease [21]. 
Table 2. The interrelations between body mass index, levels of pro- and anti-inflammatory cytokines and adipokines (Spearman's correlation coefficient, $r$ )

\begin{tabular}{|c|c|}
\hline Parameters & Correlation coefficient, $r$ \\
\hline \multicolumn{2}{|l|}{ Group 1, $n=24$} \\
\hline Leptin - Quetelet's index & $0.64 * *$ \\
\hline Leptin - IL-2 & $0.37 *$ \\
\hline Leptin - IFN- $\gamma$ & $0.55^{* *}$ \\
\hline Leptin - IL-17A & $0.64 * *$ \\
\hline Leptin - TNF- $\alpha$ & $-0.73^{* *}$ \\
\hline Adiponectin - Quetelet's index & $-0.56 * *$ \\
\hline IL-2 - IFN- $\gamma$ & $0.93^{* *}$ \\
\hline IL-2 - IL-10 & $0.38^{*}$ \\
\hline IL-17A - IL-6 & $0.45^{*}$ \\
\hline IL-17A - TNF- $\alpha$ & $-0.71 * *$ \\
\hline \multicolumn{2}{|l|}{ Group 2, $n=24$} \\
\hline Leptin - TNF- $\alpha$ & $-0.44^{*}$ \\
\hline Leptin - IL-17A & $0.54 * *$ \\
\hline Quetelet's index - IL-6 & $0.55^{* *}$ \\
\hline Quetelet's index - IL-10 & $0.69 * *$ \\
\hline Quetelet's index - IFN- $\gamma$ & $0.56 * *$ \\
\hline IL-2 - IFN- $\gamma$ & $0.65^{* *}$ \\
\hline IL-10 - IL-6 & $0.64 * *$ \\
\hline IL-10 - TNF- $\alpha$ & $0.45^{*}$ \\
\hline IL-17a - TNF- $\alpha$ & $-0.59 * *$ \\
\hline \multicolumn{2}{|l|}{ Group 3, $n=23$} \\
\hline Leptin - IL-4 & $0.61 * *$ \\
\hline Leptin - IL-17A & $0.75^{* *}$ \\
\hline Quetelet's index - IL-4 & $-0.44 *$ \\
\hline IL-17A - IL-4 & $0.82 * *$ \\
\hline IL-17A - IL-6 & $0.70 * *$ \\
\hline IL-17A - IL-10 & 0.70 \\
\hline IL-17A - IL-2 & $-0.45^{*}$ \\
\hline IL-10 - IL-4 & $0.43^{*}$ \\
\hline IL-10 - IL-6 & $0.82 * *$ \\
\hline IL-10 - TNF- $\alpha$ & $0.59 *$ \\
\hline IL-10 - IL-2 & $-0.62 *$ \\
\hline
\end{tabular}

Only statistically significant correlations between the parameters are given in this table: ${ }^{*}-p<0.05 ;^{* *}-p<0.01$.

Serum concentration of the anti-inflammatory cytokine IL-4, characterizing the state of the subpopulation of Th2 lymphocytes, was exceeded in all studied groups compared to the control group. However, there were no differences between the groups of patients. It indicates that humoral immunopathological mechanisms involve in asthma pathogenesis, as IL-4 plays a major role in Th2 immune response. At the same time, the strongest correlations of IL- 4 have been revealed in Group 3 (with leptin, IL17A and QI). These effects are due to the fact that IL-4 is an antagonist for pro-inflammatory cytokines and an increase in body weight may contribute to some depletion of the activation potential of the cells that are responsible for the production of this cytokine. Changes in the concentration of this cytokine have influenced to a certain extent the balance of cytokines and adipokines in asthma, the chronicity and the severity of the disease [22].

An elevated leptin levels and correlation links between leptin and cytokines in all groups of asthma patients indicate its association with inflammation and suggest that leptin promotes the differentiation of Th cells and the progression of autoimmune reactions, enhances the synthesis and production of a number of Th1-associated cytokines (IL-2, IL-6, TNF- $\alpha$ ) by macrophages.
Besides that, these cytokines are able to induce the secretion of leptin by mononuclear phagocytes [23].

There were no statistically significant differences in adiponectin levels between the groups. Moreover, its concentration tended to decrease in all groups. In the context of the association between obesity and asthma, adiponectin is usually considered as an anti-inflammatory cytokine, which has the ability to inhibit TNF- $\alpha$, IL-1 as well as induce the synthesis of other anti-inflammatory cytokines (IL-10). It is important to note that adiponectin concentration as a rule decreases during obesity, despite the fact that its source is adipocytes. This paradox is explained that macrophages of adipose tissue in obese patients actively produce IL- 6 and TNF- $\alpha$, which are able to directly inhibit adiponectin secretion, that leads to the loss of anti-inflammatory properties of this adipokine and, possibly, the progression of asthma [24-26].

The identified correlations between QI and leptin (positive) and adiponectin (inverse) in Group 1 can be considered taking into account the data on the dependence of adipokin level on body weight [27]. The associations of QI with IL-6, IL-10, IFN- $\gamma$ in Group 2 and with IL-4 in Group 3 confirm the literature data on the pathogenetic significance of adipose tissue in the development of asthma $[10,28]$.

The established imbalance of cytokines and adipokines and the identified correlation links indicate to the fact that cells can change the intensity of production of particular cytokines during the development of Th1, Th2, Th17 immune response. The obtained data have shown that the development of immune response is determined by the search for the middle ground between the types of Th immune response.

\section{Conclusion}

The production of pro-inflammatory cytokines IL-6 and IL-17A as well as anti-inflammatory cytokine IL-10 enhances in patients with partially controlled mild as the body weight increases and the obesity develops. The features of cytokine and adipokine imbalance indicates the prevalence of neutrophilic inflammation in asthma associated with obesity. The established correlation links indicate the important immune-pathophysiological role of hyperleptinemia and pro- and anti-inflammatory cytokines in the formation of asthma with obesity and provide the pathogenetic association of obesity and asthma, largely determining the direction, severity and outcome of the pathological process.

\section{Limitations}

The limitations of this study are related to the fact that it was performed only in a group of patients with partially controlled mild asthma. The obtained results may differ from those in a group of patients with more severe asthma of varying degrees of control.

\section{Ethical approval}

The study was conducted in accordance with the Declaration of Helsinki (2013), and the protocol was approved by the Ethics Committee of the Vladivostok Branch of Far Eastern Scientific Center of Physiology and Pathology of Respiration, Research Institute of Medical Climatology and Rehabilitative Treatment.

\section{Conflict of interest}

We declare that we have no conflict of interest. 


\section{References}

1. Astafieva NG, Gamova IV, Udovichenko EN, Perfilova IA. Obesity and bronchial asthma. Attending physician 2014; (5): 100-107. Russian. https://elibrary.ru/item.asp?id=21504948.

2. Ignatova GL, Makarova EA. Bronchial asthma and obesity: clinical and pathogenetic aspects of the selection of new phenotype. Modern problems of science and education 2016; (4): 88. Russian. https://elibrary.ru/item.asp?id=26532879

3. Petrov RV, Khaitov RM, Chereshnev VA. Physiology of the immune system: Cellular and Molecular-Biological Mechanisms. RFBR Journal 2017; (1(Special issue)): 96-119. Russian. https://www.rfbr.ru/rffi/ru/bulletin/o 2051564\#96.

4. Simbirtsev AS. Cytokines in the pathogenesis of infectious and noninfectious human diseases. Medical academic journal 2013; 13(3): 18-41. https://elibrary.ru/item.asp?id=20724602.

5. Mineev VN, Lalaeva TM, Trofimov VI. Bronchial asthma and obesity: common mechanisms. Clinical medicine 2012; 90(4): 4-10. Russian. https://elibrary.ru/item.asp?id=18045606.

6. Gibeon D, Batuwita K, Osmond M, Heaney LG, Brightling CE, Niven R, et al. Obesity-associated severe asthma represents a distinct clinical phenotype: analysis of the British Thoracic Society Difficult Asthma Registry Patient cohort according to BMI. Chest 2013; 143(2): 406-414. https://doi.org/10.1378/chest.12-0872.

7. Tsibulkina VN, Tsybulkin NA. Asthma and obesity: coincidence or pattern? Practical medicine 2011; (6(54)): 36-41. Russian. https://elibrary.ru/item.asp?id=17042300.

8. Pristupa LN, Fadeeva AA. Relationships of asthma and obesity. Russian Pulmonology 2012; (3): 97-103. Russian https://doi.org/10.18093/0869-0189-2012-0-3-97-103.

9. Lugogo NL, Kraft M, Dixon AE. Does obesity produce a distinct asthma phenotype? J Appl Physiol 2010; 108(3): 729-734. https://doi.org/10.1152/japplphysiol.00845.2009.

10. Sood A, Shore SA. Adiponectin, leptin, and resistin in asthma: basic mechanisms through population studies. J Allergy (Cairo) 2013; 2013: 785835. https://doi.org/10.1155/2013/785835.

11. Pirogov AB, Prikhodko AG, Perelman JM, Zinov'ev SV, Afanas'eva EYu. Phenotypical features of bronchial inflammation in patients with asthma with different types of airway response to hyposmolar and gold stimuli. Bulletin Physiology and Pathology of Respiration 2015; (58): 8-14. Russian. https://elibrary.ru/item.asp?id=25013399\&.

12. Avdeev SN, Nenasheva NM, Zhudenkov KV, Petrakovskaya VA Izyumova GV. Prevalence, morbidity, phenotypes and other characteristics of severe bronchial asthma in Russian Federation. Russian Pulmonology 2018; 28(3): 341-358. Russian. https://doi.org/10.18093/0869-0189-2018-28-3-341-358.

13. Global Initiative for Asthma (GINA). Global strategy for asthma management and prevention. 2017. https://ginasthma.org/wpcontent/uploads/2019/04/wmsGINA-2017-main-report-final_V2.pdf.

14. Juniper EF, Bousquet J, Abetz L, Bateman ED. Identifying 'wellcontrolled' and 'not well-controlled' asthma using the Asthma Control Questionnaire. Respir Med 2006; 100(4): 616-621. https://doi.org/10.1016/i.rmed.2005.08.012.

15. Pellegrino R, Viegi G, Brusasco V, Crapo RO, Burgos F, Casaburi R, et al. Interpretative strategies for lung function tests. Eur. Respir. J. 2005; 26(5): 948-968. https://doi.org/10.1183/09031936.05.00035205.

16. BMI classification. WHO. http://www.euro.who.int/en/healthtopics/disease-prevention/nutrition/a-healthy-lifestyle/body-massindex-bmi.

17. Kurbacheva OM, Zhestkov AV, Nagatkin DA, Kulagina VV, Nagatkina OV. Modern view on immunopathogenesis of asthma. Russian Allergology J 2016; (2): 10-14. Russian. https://elibrary.ru/item.asp?id=25969699.

18. Murasov EG, Stolov SV, Totolian AA. Cytokines profile bronchoalveolar lavage patients wiht bronchial asthma. Herald of the North-Western
State Medical University named after I.I. Mechnikov 2015; 7 (1): 115121. Russian. https://elibrary.ru/item.asp?id=24307747.

19. Lazutkina EL. The pathogenetic importance of pro- and antiinflammatory cytokines in patients with bronchial asthma and obesity. Amur medical journal 2016; (2(14)): 26-29. Russian. https://elibrary.ru/item.asp?id=26467838.

20. Bhakta NR, Erle DJ. IL-17 and «TH2-high» asthma: Adding fuel to the fire? J Allergy Clin Immunol 2014; 134(5): 1187-1188. https://doi.org/10.1016/j.jaci.2014.07.034.

21. Ogawa Y, Duru EA, Ameredes BT. Role of IL-10 in the Resolution of Airway Inflammation. Curr Mol Med 2008; 8(5): 437-445. https://doi.org/10.2174/156652408785160907.

22. Cui AH, Zhao J, Liu SX, Hao YS. Associations of IL-4, IL-6, and IL-12 levels in peripheral blood with lung function, cellular immune function, and quality of life in children with moderate-to-severe asthma. Medicine (Baltimore) 2017; 96(12): e6265. https://doi.org/10.1097/MD.0000000000006265.

23. Procaccini $\mathrm{C}$, Jirillo $\mathrm{E}$, Matarese $\mathrm{G}$. Leptin as an immunomodulator. $\mathrm{Mol}$ Aspects Med 2012; 33(1): 35-45. https://doi.org/10.1016/j.mam.2011.10.012.

24. Sood A, Seagrave J, Herbert G, Harkins M, Alam Y, Chiavaroli A, et al. High sputum total adiponectin is associated with low odds for asthma. J Asthma 2014; 51(5): 459-466. https://doi.org/10.3109/02770903.2014.882934.

25. Yamamoto R, Ueki S, Moritoki Y, Kobayashi Y, Oyamada H, Konno Y, et al. Adiponectin attenuates human eosinophil adhesion and chemotaxis: implication in allergic inflammation. J Asthma 2013; 50(8); 828-835. https://doi.org/10.3109/02770903.2013.816725.

26. de Lima Azambuja R, da Costa Santos Azambuja LS, Costa C, Rufino R. Adiponectin in asthma and obesity: protective agent or risk factor for more severe disease? Lung 2015; 193(5): 749-755. https://doi.org/10.1007/s00408-015-9793-8.

27. Boyarinova MA, Orlov AV, Rotar OP, Alieva AS, Moguchaya EV, Vasileva EU, et al. Adipokines Level in Metabolically Healthy Obese Saint-Petersburg Inhabitants (ESSE-RF). Kardiologiia 2016; 56(8): 4045. Russian. https://elibrary.ru/item.asp?id=27174503

28. Mineev VN, Lalaeva TM, Nesterovich II. Adipokine signaling in bronchial asthma in combination with overweight. Vestnik SPbSU. Medicine 2016; (3): 5-19. Russian. https://elibrary.ru/item.asp?id=28089286.

\section{Authors:}

Alla V. Yurenko - MD, PhD, Researcher, Laboratory of Rehabilitative Treatment, Vladivostok Branch of Far Eastern Scientific Centre of Physiology and Pathology of Respiration, Research Institute of Medical Climatology and Rehabilitative Treatment, Vladivostok, Russia. https://orcid.org/0000-0003-0396-6380.

Marina V. Antonyuk - MD, DSc, Professor, Head of Laboratory of Rehabilitative Treatment, Vladivostok Branch of Far Eastern Scientific Centre of Physiology and Pathology of Respiration, Research Institute of Medical Climatology and Rehabilitative Treatment, Vladivostok, Russia. https://orcid.org/0000-0002-2492-3198.

Elena E. Mineeva - MD, PhD, Researcher, Laboratory of Rehabilitative Treatment, Vladivostok Branch of Far Eastern Scientific Centre of Physiology and Pathology of Respiration, Research Institute of Medical Climatology and Rehabilitative Treatment, Vladivostok, Russia. https://orcid.org/0000-0002-4286-2827.

Tatyana P. Novgorodtseva - DSc, Professor, Chief Researcher, Laboratory of Biomedical Research, Vladivostok Branch of Far Eastern Scientific Centre of Physiology and Pathology of Respiration, Research Institute of Medical Climatology and Rehabilitative Treatment, Vladivostok, Russia. https://orcid.org/0000-0002-6058-201X.

Kira K. Khodosova - Junior Researcher, Laboratory of Biomedical Research, Vladivostok Branch of Far Eastern Scientific Centre of Physiology and Pathology of Respiration, Research Institute of Medical Climatology and Rehabilitative Treatment, Vladivostok, Russia. https://orcid.org/0000 0001-7208-992X. 